Original article

\title{
The efficacy of cariprazine in negative symptoms of schizophrenia: Post hoc analyses of PANSS individual items and PANSS-derived factors
}

\author{
Wolfgang Fleischhacker ${ }^{\mathrm{a}}$, Silvana Galderisi ${ }^{\mathrm{b}}$, István Laszlovszky ${ }^{\mathrm{c}, *}$, Balázs Szatmáric, \\ Ágota Barabássyc ${ }^{\mathrm{c}}$, Károly Acsaic ${ }^{\mathrm{C}}$ Erzsébet Szalai ${ }^{\mathrm{C}}$, Judit Harsányi ${ }^{\mathrm{C}}$, Willie Earley ${ }^{\mathrm{d}}$, \\ Mehul Patel $^{\mathrm{d}}$, György Németh ${ }^{\mathrm{c}}$
}

\footnotetext{
a Department of Psychiatry, Psychotherapy and Psychosomatics, Medical University Innsbruck, Innsbruck, Austria

${ }^{\mathrm{b}}$ Department of Psychiatry, University of Naples (SUN), Naples, Italy

${ }^{\mathrm{c}}$ Medical Division, Gedeon Richter Plc, Budapest, Hungary

d Allergan, Madison, NJ, USA
}

\section{A R T I C L E I N F O}

Article history:

Received 19 September 2018

Received in revised form 9 January 2019

Accepted 12 January 2019

Available online 7 February 2019

\section{Keywords:}

Cariprazine

Risperidone

Schizophrenia

Negative symptoms

PANSS

Cognition

\begin{abstract}
A B S T R A C T
Background: Negative symptoms in schizophrenia are heterogeneous and multidimensional; effective treatments are lacking. Cariprazine, a dopamine $D_{3}$-preferring $D_{3} / D_{2}$ receptor partial agonist and serotonin $5-\mathrm{HT}_{1 \mathrm{~A}}$ receptor partial agonist, was significantly more effective than risperidone in treating negative symptoms in a prospectively designed trial in patients with schizophrenia and persistent, predominant negative symptoms.

Methods: Using post hoc analyses, we evaluated change from baseline at week 26 in individual items of the Positive and Negative Syndrome Scale (PANSS) and PANSS-derived factor models using a mixedeffects model for repeated measures (MMRM) in the intent-to-treat (ITT) population (cariprazine $=227$; risperidone $=227$ ).

Results: Change from baseline was significantly different in favor of cariprazine versus risperidone on PANSS items N1-N5 (blunted affect, emotional withdrawal, poor rapport, passive/apathetic social withdrawal, difficulty in abstract thinking) $(P<.05)$, but not on N6 (lack of spontaneity/flow of conversation) or N7 (stereotyped thinking). On all PANSS-derived negative symptom factor models evaluated (PANSS-Factor Score for Negative Symptoms, Liemburg factors, Khan factors, Pentagonal Structure Model Negative Symptom factor), statistically significant improvement was demonstrated for cariprazine versus risperidone $(P<.01)$. Small and similar changes in positive/depressive/EPS symptoms suggested that negative symptom improvement was not pseudospecific. Change from baseline was significantly different for cariprazine versus risperidone on PANSS-based factors evaluating other relevant symptom domains (disorganized thoughts, prosocial function, cognition; $P<.05$ ).

Conclusions: Since items representing different negative symptom dimensions may represent different fundamental pathophysiological mechanisms, significant improvement versus risperidone on most PANSS Negative Subscale items and across all PANSS-derived factors suggests broad-spectrum efficacy for cariprazine in treating negative symptoms of schizophrenia.
\end{abstract}

(C) 2019 The Authors. Published by Elsevier Masson SAS. This is an open access article under the CC BY license (http://creativecommons.org/licenses/by/4.0/).

\section{Introduction}

Schizophrenia, an often chronic and debilitating psychiatric disorder, is characterized by a constellation of clinical signs and symptoms that are categorized into distinct positive, negative, disorganization and cognitive symptom domains. Although

\footnotetext{
* Corresponding author at: Gedeon Richter Plc, Medical Division, H-1103 Budapest, Gyomroi ut 19-21., Hungary.

E-mail address: i.laszlovszky@richter.hu (I. Laszlovszky).
}

positive symptoms (eg, delusions, hallucinations) must be present for a diagnosis of schizophrenia to be made, negative symptoms, typified by the absence of normal function and loss of behaviors and motivation, are highly detrimental to patient functioning and quality of life [1-7]. While antipsychotic treatment is effective against positive schizophrenia symptoms, effective treatment for negative symptoms is lacking and most improvement occurs secondarily to improvement in positive symptoms [1]. Research suggests that negative symptoms are heterogeneous, with potentially different pathophysiological mechanisms and psychopathological outcomes $[8,9]$. As such, understanding how an 
antipsychotic performs across the range of negative symptoms may help improve clinical management of this fundamental dimension of schizophrenia.

Through efforts to consolidate the negative symptom concept [10-13], broad consensus has emerged that the most prominent constructs are the $5 \mathrm{~A}$ 's of negative symptoms: affective flattening, alogia, anhedonia, asociality, and avolition [12,14]. Briefly, blunted affect is a decrease in observed expression of emotion; alogia is reduced quantity of speech/spontaneous information; anhedonia is the diminished capacity to experience pleasure during an event (consummatory anhedonia) or in anticipation of one (anticipatory anhedonia); asociality is reduced social initiative due to decreased interest in forming and maintaining relationships; and avolition is reduced initiation/persistence of goal-directed activity. The Positive and Negative Syndrome Scale (PANSS) [15] is a frequently used clinical rating scale, which generally includes items to evaluate the 5 A's. Although newer scales have been developed to more specifically assess negative symptoms $[13,16]$ and the PANSS has limitations, no consensus has been reached regarding the best rating scale for assessing negative symptoms in schizophrenia.

The negative symptom structure is multidimensional, with evidence emerging in support of models generally consisting of 2-5 factors [10]. The most stable and replicated models include 2 factors clustering into the potentially related but distinct subdomains of diminished expression (ie, blunted affect, alogia) and avolition/apathy (ie, avolition, asociality, anhedonia) [8]; this model is supported in the fifth edition of the Diagnostic and Statistical Manual of Mental Disorders (DSM-5) [2]. Interestingly, just as it is proposed that negative and positive symptoms have different pathophysiological mechanisms, evidence suggests similar underlying differences within the negative symptom subdomains [12].

Cariprazine, an orally active and potent dopamine $\mathrm{D}_{3}$-preferring $\mathrm{D}_{3} / \mathrm{D}_{2}$ receptor partial agonist and serotonin $5-\mathrm{HT}_{1 \mathrm{~A}}$ receptor partial agonist $[17,18]$, is approved for the treatment of adult patients with schizophrenia (Europe and US) and for acute treatment of manic/ mixed episodes of bipolar I disorder (US). Unlike other atypical antipsychotics, cariprazine shows high and balanced in vivo occupancy at dopamine $D_{2}$ and $D_{3}$ receptors at clinically relevant doses [17,19]. In animal models, cariprazine has demonstrated dopamine $\mathrm{D}_{3}$ receptor-dependent procognitive and anti-anhedonic effects, suggesting that it may be useful in treating negative symptoms of schizophrenia $[20,21]$.

In a 26-week randomized, double-blind, active-comparator controlled study, cariprazine and risperidone were compared in stable patients with schizophrenia and persistent, predominant negative symptoms (PPNS) (EudraCT Number 2012-005485-36) [22]. Cariprazine was significantly more effective than risperidone in improving negative symptoms as shown by change from baseline to week 26 on the primary efficacy parameter, the PANSS Factor Score for Negative Symptoms (PANSS-FSNS) [23], which is also known as the Marder factor for Negative Symptoms [24]. A significant between-group difference for cariprazine versus risperidone was also seen on the secondary efficacy parameter, the Personal and Social Performance Scale (PSP) [25], demonstrating that negative symptom improvement was accompanied by improvement in dayto-day functioning for cariprazine-treated patients.

This well-designed large-scale study in patients with schizophrenia and PPNS provided important evidence of the clinically significant superiority of cariprazine over another second-generation antipsychotic in treating negative symptoms. To further evaluate negative symptom improvement with cariprazine in prospectively defined patients with schizophrenia and PPNS, we assessed changes in PANSS individual subscale items and PANSSderived factors using post hoc analyses. Given the results of the original trial, we expect that our more detailed investigations will show that cariprazine has greater efficacy than risperidone on negative symptoms and related constructs when change from baseline to week 26 is assessed using PANSS individual items and PANSS-derived factors.

\section{Materials and methods}

\subsection{Primary study design}

Detailed methods of the prospective cariprazine versus risperidone study (RGH-188-005) have been published [22]. Briefly, the study consisted of a 4-week lead-in period, 26-week double-blind treatment (2-week up-titration and 24-week continuation treatment), and a 2 -week safety follow-up. Patients were randomized $(1: 1)$ to once-daily oral cariprazine or risperidone; after up-titration, patients received the target dose of cariprazine $(4.5 \mathrm{mg} / \mathrm{d})$ or risperidone $(4 \mathrm{mg} / \mathrm{d})$. The target dose could be decreased or increased (once time each) in case of poor tolerability or impending psychotic deterioration during the double-blind continuation phase. The accepted fixed doses of cariprazine $(3,4.5$, or $6 \mathrm{mg} / \mathrm{d}$ ) and risperidone $(3,4$, or $6 \mathrm{mg} / \mathrm{d}$ ) were chosen in accordance with the respective product labels.

\subsection{Patients}

Male and female patients (18-65 years old, inclusive) who participated in the study had a DSM-IV-TR [26] diagnosis of schizophrenia and an available psychiatric history to ensure the presence of PPNS and low levels of positive symptoms. Patients had an illness duration $\geq 2$ years and a stable condition for at least 6 months (ie, no acute exacerbations, psychiatric hospitalizations, or imprisonments). Clinical inclusion criteria required PPNS for $\geq 6$ months, PANSS-FSNS score $\geq 24$, and a score $\geq 4$ on at least 2 of 3 PANSS negative symptom items (blunted affect, passive/apathetic social withdrawal, lack of spontaneity/flow of conversation).

Patients were excluded from the primary study for various reasons, including a current DSM-IV-TR axis I disorder other than schizophrenia or unstable clinical condition. Most importantly, clinical criteria excluded patients with moderate-to-severe positive, depressive, and extrapyramidal symptoms (EPS) to ensure that negative symptom changes could be genuinely attributed to improved negative symptoms and not to secondary improvements in these other psychopathological domains (ie, pseudospecific improvement). Specifically, patients were excluded for: score $\geq 4$ on more than 2 specific PANSS items (P1 [delusions], P3 [hallucinatory behavior], P5 [grandiosity], P6 [suspiciousness], G9 [unusual thought content]); PANSS factor score for Positive Symptoms (PANSS-FSPS) >19 [27]; total score >6 (moderate/ severe symptoms) on the Calgary Depression Scale for Schizophrenia (CDSS) [28]; or clinically relevant parkinsonian symptoms as judged by an investigator and/or defined as a sum $>3$ on the first 8 items of the Simpson Angus Scale (SAS) [29].

\subsection{Post hoc analyses}

Changes from baseline to week 26 on the single items of the PANSS Negative Symptom and General Psychopathology subscales (Table 1 ) were analyzed to investigate the efficacy of cariprazine on individual symptoms that contribute to heterogeneity in schizophrenia pathology. To assess the multidimensional aspect of negative symptoms, changes from baseline to week 26 on the individual items of the PANSS-FSNS were evaluated. Additional PANSS-derived factors for negative symptoms [30-33] were located through an extensive search of the literature and our data were further analyzed using these models (Table 1). Factors of interest in other domains (supplementary Table 1), including 
Table 1

PANSS-derived negative symptoms factors.

\begin{tabular}{|c|c|c|c|c|c|c|}
\hline \multirow[t]{2}{*}{ PANSS Items } & \multirow[b]{2}{*}{ FSNS $^{\mathrm{a}}$} & \multicolumn{2}{|l|}{ Liemburg } & \multicolumn{2}{|l|}{ Khan $^{\mathrm{c}}$} & \multirow{2}{*}{$\begin{array}{l}\text { PSM Negative } \\
\text { Factor }\end{array}$} \\
\hline & & $\begin{array}{l}\text { Avolition/ } \\
\text { Asociality }^{\mathrm{b}}\end{array}$ & $\begin{array}{l}\text { Expressive } \\
\text { Deficit }\end{array}$ & $\begin{array}{l}\text { Expressive } \\
\text { Deficit }\end{array}$ & $\begin{array}{l}\text { Experiential } \\
\text { Deficit }^{\mathrm{b}}\end{array}$ & \\
\hline \multicolumn{7}{|l|}{ Negative Symptom Subscale } \\
\hline N1: Blunted affect & 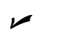 & & レ & $\boldsymbol{\nu}$ & & $\boldsymbol{\nu}$ \\
\hline N2: Emotional withdrawal & $\nu$ & 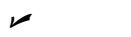 & & & $\boldsymbol{r}$ & レ \\
\hline N3: Poor rapport & レ & & レ & $\boldsymbol{\nu}$ & & $\nu$ \\
\hline $\begin{array}{l}\text { N4: Passive/ } \\
\text { apathetic social withdrawal } \\
\text { N5: Difficulty in abstract think }\end{array}$ & & 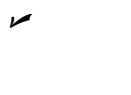 & & & $\boldsymbol{r}$ & レ \\
\hline $\begin{array}{l}\text { N6: Lack of spontaneity/ } \\
\text { flow of conversation }\end{array}$ & レ & & レ & レ & & $\boldsymbol{v}$ \\
\hline \multicolumn{7}{|c|}{ N7: Stereotyped thinking } \\
\hline \multicolumn{7}{|c|}{ General Psychopathology Subscale } \\
\hline \multicolumn{7}{|c|}{ G1: Somatic concern } \\
\hline \multicolumn{7}{|l|}{ G2: Anxiety } \\
\hline \multicolumn{7}{|l|}{ G3: Guilt feelings } \\
\hline \multicolumn{7}{|l|}{ G4: Tension } \\
\hline $\begin{array}{l}\text { G5: Mannerisms/ } \\
\text { posturing }\end{array}$ & & & レ & & & $\boldsymbol{\nu}$ \\
\hline \multicolumn{7}{|l|}{ G6: Depression } \\
\hline G7: Motor retardation & $\nu$ & & レ & $\nu$ & & $\boldsymbol{\nu}$ \\
\hline G8: Uncooperativeness & & & & & & レ \\
\hline \multicolumn{7}{|l|}{ G9: Unusual thought content } \\
\hline \multicolumn{7}{|l|}{ G10: Disorientation } \\
\hline \multicolumn{7}{|l|}{ G11: Poor attention } \\
\hline \multicolumn{7}{|l|}{ G12: Lack of judgement/insight } \\
\hline G13: Disturbance of volition & & & レ & & & $\boldsymbol{\nu}$ \\
\hline G14: Poor impulse control & & & & & & レ \\
\hline \multicolumn{7}{|l|}{ G15: Preoccupation } \\
\hline G16: Active social avoidance & $\nu$ & 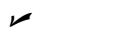 & & & $v$ & \\
\hline
\end{tabular}

FSNS, Factor Score for Negative Symptoms; PANSS, Positive and Negative Syndrome Scale; PSM, Pentagonal Structure Model.

a Also known as the Marder Factor for Negative Symptoms.

b The same items comprise the Liemburg Avolition/Asociality factor and the Khan Experiential Deficit factor.

c Also known as the Fervaha 2-factor model: the Fervaha Amotivation factor and Khan Experiential Deficit factor are identical, and the Fervaha Diminished Expression factor and Khan Expressive Deficit factor are identical.

disorganized thoughts (items N5, P2, G5, G10-11, G13, G15) [24], prosocial function (items N2, N4, N7, P3, P6, G16) [34], and cognition (items N5, N7, P2, G10-11) [35], were also evaluated. Furthermore, the possibility that negative symptom improvement was related to improvement in positive symptoms was investigated via changes on the individual items of the PANSS Positive subscale (items P1-7) and PANSS-FSPS (items P1, P3, P5-6, G9); Marder factors for Depression/Anxiety (items G2-4, G6), Uncontrolled Hostility/Excitement (items P4, P7, G8, G14), and Positive Symptoms (N7, P1, P3, P5-6, G1, G9, G12) were also analyzed as contols for pseudospecificity [24] (supplementary Table 1).

Analyses of PANSS single items and factors were based on all postbaseline scores using observed cases without imputing missing values; the final assessment was omitted if the study drug had been stopped for more than 5 days. Change from baseline to week 26/endpoint in individual PANSS items and PANSS factors was analyzed using a mixed-effects model for repeated measures (MMRM) with treatment group, visit, study center, and treatment group-by-visit interaction as fixed effects, and the baseline value and baseline value-by-visit interaction as the covariates in the intent-to-treat (ITT) population. Analyses were performed in SAS (PROC MIXED) (Version 9.2. Cary, NC: SAS Institute Inc. 2012), using an unstructured covariance matrix to model the covariance of within-patient scores; the resultant F-tests were based on Kenward-Roger's adjusted denominator degrees of freedom [36].

\section{Results}

In the primary, prospective study (RGH-188-005), a total of 461 patients were randomized to double-blind treatment (cariprazine $=$ 230; risperidone $=231$ ); 456 patients were included in the ITT population (cariprazine $=227$; risperidone $=229$ ) [22]. The least squares mean difference with $95 \%$ confidence interval (LSMD [95\% $\mathrm{CI}]$ ) was statistically significant in favor of cariprazine versus risperidone on the PANSS-FSNS $(-1.46[-2.39,-0.53] ; P=.0022$; effect size $=0.31)$ and the PSP $(4.63[2.71,6.56] ; P<.0001$; effect size $=0.48$ ).

\subsection{Post hoc analyses}

\subsubsection{Baseline values}

Mean baseline values for individual PANSS Negative and Positive subscale items were similar between groups (Table 2) and supported that inclusion criteria succeeded in selecting a patient population with at least moderate negative symptoms and mild positive symptoms. Although general items are inconsistently related to the negative symptom subdomain, items from the General Psychopathology subscale often map to negative symptom factors. Of interest, several general items that map to negative symptom factors or to the Disorganized Thought/Cognition factor (ie, G5, G7, G11, G13, G15, G16) were among the general items with higher baseline scores. As expected given the study's inclusion criteria, scores for general items that map to the Marder Depression factor (G2, G3, G4, G6) were generally low.

Mean baseline values on the first 8 items of the SAS (gait, arm dropping, shoulder shaking, elbow rigidity, wrist rigidity, leg pendulousness, head dropping, glabella tap) ranged from 0 to 0.4 , indicating a population without clinically significant parkinsonism (score range per item $=0-4$; lower scores indicate less severe symptoms). Baseline CDSS total score values (score range $=0-27$; lower score is favorable) indicated a population without substantial depressive symptoms (cariprazine $=0.7$; risperidone $=0.9$ ). 
Table 2

Baseline values for PANSS Negative and Positive Symptom subscales single items (ITT population).

\begin{tabular}{|c|c|c|}
\hline \multirow[t]{2}{*}{ PANSS } & \multicolumn{2}{|c|}{ Mean Baseline Value } \\
\hline & $\begin{array}{l}\text { Cariprazine } \\
\mathrm{n}=227\end{array}$ & $\begin{array}{l}\text { Risperidone } \\
\mathrm{n}=229\end{array}$ \\
\hline \multicolumn{3}{|l|}{ Negative Symptom Subscale } \\
\hline N1: Blunted affect & 4.5 & 4.4 \\
\hline N2: Emotional withdrawal & 4.3 & 4.3 \\
\hline N3: Poor rapport & 3.9 & 3.8 \\
\hline N4: Passive/apathetic social withdrawal & 4.6 & 4.6 \\
\hline N5: Difficulty in abstract thinking & 3.7 & 3.7 \\
\hline N6: Lack of spontaneity and flow of conversation & 4.1 & 4.1 \\
\hline N7: Stereotyped thinking & 3.4 & 3.4 \\
\hline \multicolumn{3}{|l|}{ Positive Symptom Subscale } \\
\hline P1: Delusions & 1.9 & 1.9 \\
\hline P2: Conceptual disorganization & 2.6 & 2.6 \\
\hline P3: Hallucinatory behavior & 1.4 & 1.4 \\
\hline P4: Excitement & 1.5 & 1.4 \\
\hline P5: Grandiosity & 1.2 & 1.3 \\
\hline P6: Suspiciousness/persecution & 2.2 & 2.1 \\
\hline P7: Hostility & 1.2 & 1.2 \\
\hline \multicolumn{3}{|l|}{ General Psychopathology Subscale } \\
\hline G1: Somatic concern & 1.7 & 1.6 \\
\hline G2: Anxiety & 1.9 & 2.1 \\
\hline G3: Guilt feelings & 1.3 & 1.3 \\
\hline G4: Tension & 1.8 & 2.0 \\
\hline G5: Mannerisms/posturing & 2.6 & 2.5 \\
\hline G6: Depression & 1.5 & 1.5 \\
\hline G7: Motor retardation & 3.2 & 3.1 \\
\hline G8: Uncooperativeness & 1.5 & 1.5 \\
\hline G9: Unusual thought content & 2.0 & 2.0 \\
\hline G10: Disorientation & 1.8 & 1.8 \\
\hline G11: Poor attention & 3.1 & 3.0 \\
\hline G12: Lack of judgement/insight & 3.1 & 3.1 \\
\hline G13: Disturbance of volition & 3.5 & 3.4 \\
\hline G14: Poor impulse control & 1.4 & 1.4 \\
\hline G15: Preoccupation & 2.6 & 2.8 \\
\hline G16: Active social avoidance & 3.1 & 3.1 \\
\hline
\end{tabular}

PANSS item scores range from 1-7. Lower scores indicate less severe symptoms.

PANSS, Positive and Negative Syndrome Scale.

3.1.2. Individual items of the negative symptom and general psychopathology subscales

On individual items from the PANSS Negative Symptom subscale, LSMDs in change from baseline were statistically significant in favor of cariprazine versus risperidone on most items (Fig. 1A). Mean change by week in the individual items of the PANSS Negative Symptom subscale is presented in online supplementary material (Fig.1A-G). Differences in mean change on several items evaluating the $5 \mathrm{~A}$ 's of negative symptoms were statistically significant in favor of cariprazine versus risperidone (ie, affect blunted: N1; avolition: $\mathrm{N} 2$ [emotional withdrawal]; asociality: N3 [poor rapport] and N4 [passive/apathetic social withdrawal]). Because there is no specific PANSS item for anhedonia, this construct must be evaluated indirectly through negative symptom items that may be descriptive of the concept. For example, change was greater for cariprazine than risperidone on items $\mathrm{N} 2$ and $\mathrm{N} 4$ evaluating lack of interest in life events and diminished interest/involvement in social interactions leading to reduced personal involvement and neglect of daily activities, respectively [11]. On the key construct of alogia, measured by item N6, a greater than 1-point improvement was seen in both the cariprazine- and risperidone-treatment groups, but the betweengroup difference was not statistically significant.

Changes from baseline to week 26 on the individual items of the General Psychopathology subscale were small (range, -0.14 to -1.12 ) and generally similar between groups; significant differences were seen on only 2 items, active social avoidance (G16) in favor of cariprazine over risperidone $(P=.042)$, and guilt feelings (G3) in favor risperidone over cariprazine $(P=.048)$ (Fig. 1B).

\subsubsection{PANSS-derived factors supporting a treatment effect for cariprazine}

On the individual items of the PANSS-FSNS, significant differences in change from baseline at week 26 were seen in favor of cariprazine over risperidone on 4 of the 5 negative symptom items included in the factor (N1, N2, N3, N4); no between-group difference was noted for N6 (Fig. 1A). For items included from the General Psychopathology subscale, a significant difference in favor of cariprazine was seen on item G16, but not on item G7 (Fig. 1B).

In this PPNS population, prospective PANSS-FSNS results were supported by significant differences in favor of cariprazine over risperidone in change from baseline on other PANSS-derived factors evaluating negative symptoms (Fig. 2). On the 2-factor model utilized by Liemburg at al, mean changes from baseline were significantly greater for cariprazine versus risperidone on the Avolition/Social Amotivation (-3.60 vs -2.98; $P=.004)$ and Expressive Deficit ( -6.75 vs $-5.66 ; P=.004)$ factors. Similarly, in the $2-$ factor model utilized by Khan et al and Fervaha et al, the difference in mean change from baseline on the Khan Expressive Deficit factor (also known as the Fervaha Diminished Expression factor) was statistically significant for cariprazine $(-5.36)$ versus risperidone $(-4.48 ; P=.003)$; the same items are included in the Liemburg Avolition/Asociality factor, the Khan Experiential Deficit factor, and the Fervaha Amotivation factor. Finally, mean change from baseline was again significantly different in favor of cariprazine (-9.85) versus risperidone $(-8.25 ; P=.003)$ on the Pentagonal Structure Model (PSM) Negative Symptom factor score.

On factors assessing changes in domains relevant to negative symptoms, differences in mean change from baseline at week 26 

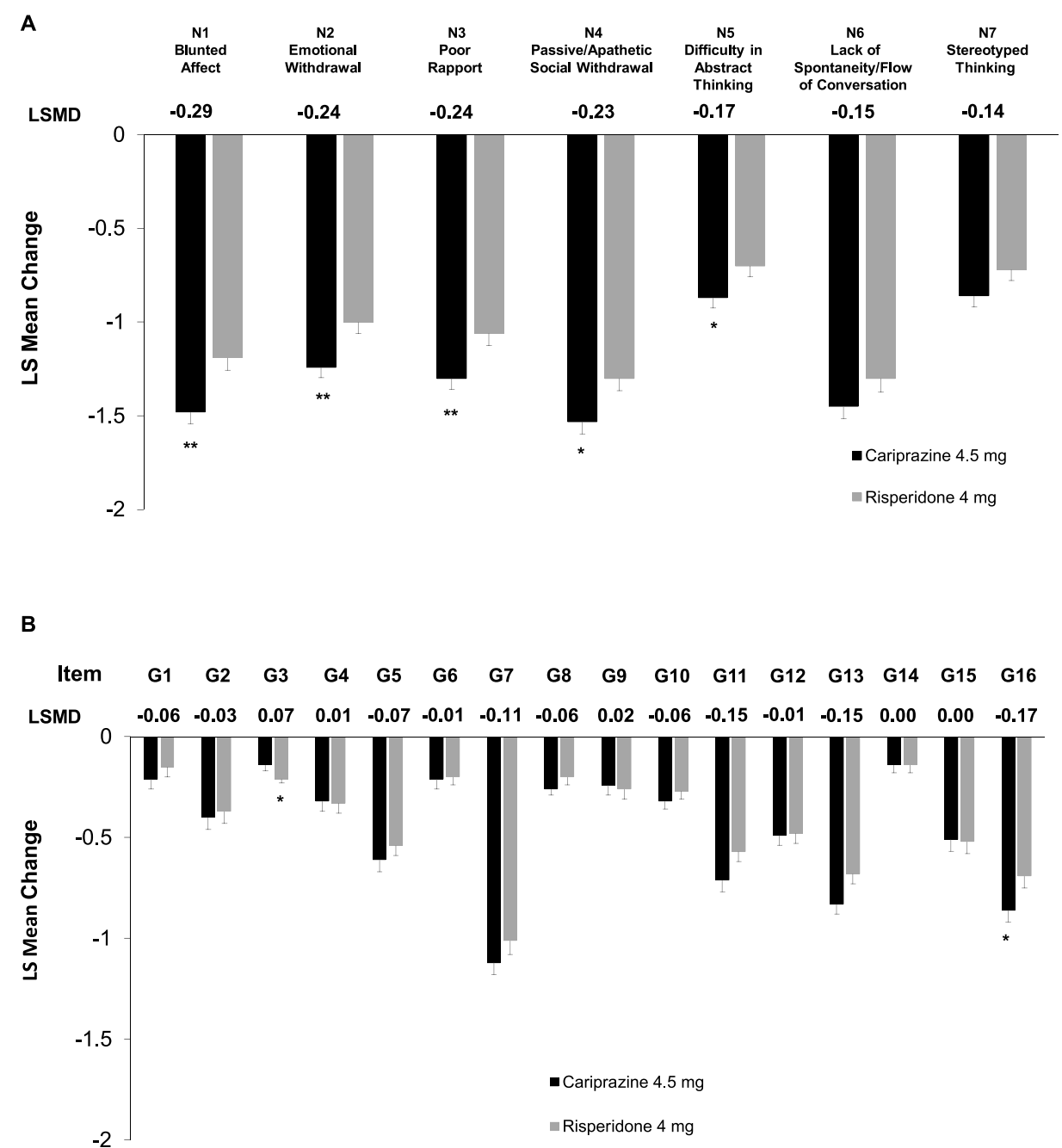

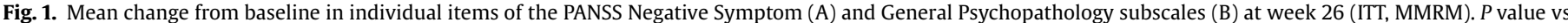

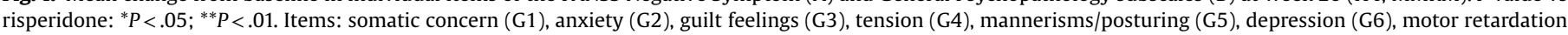

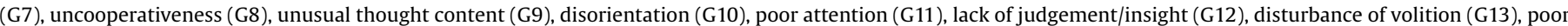

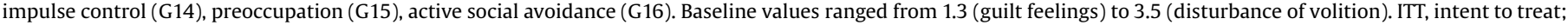
LS, least squares; LSMD, least squares mean difference; MMRM, mixed-effects model for repeated measures; PANSS, Positive and Negative Syndrome Scale.

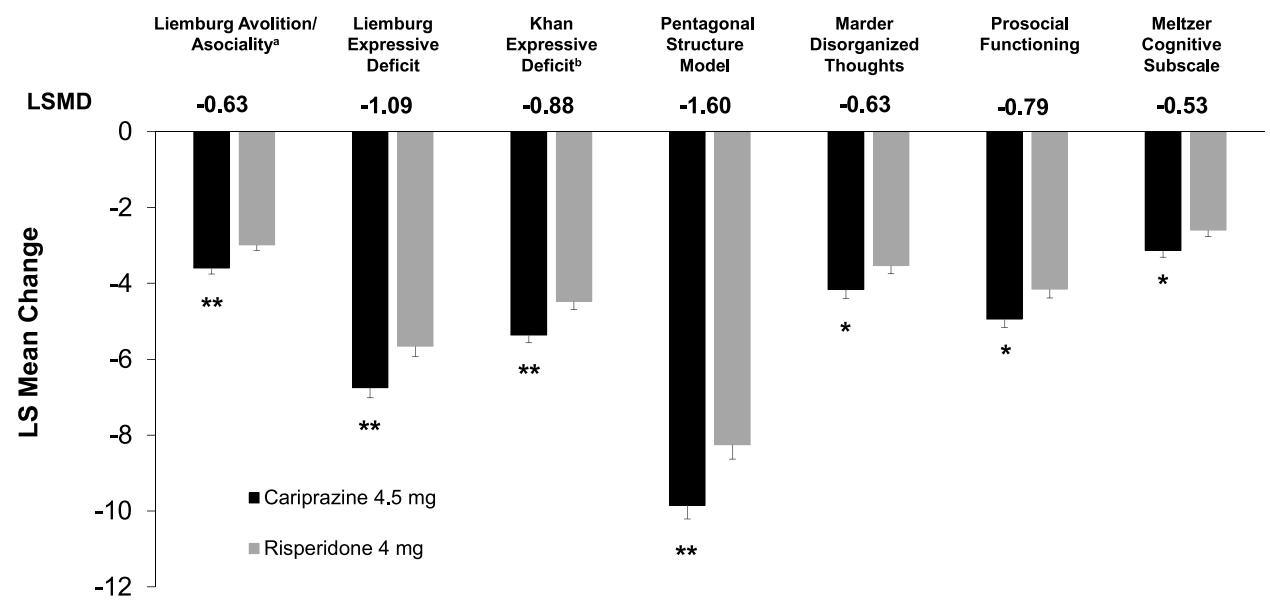

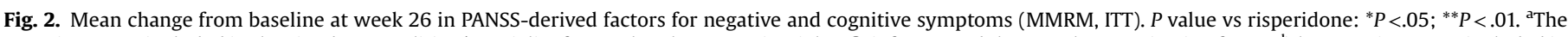

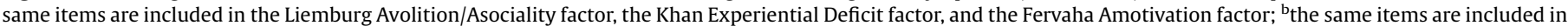

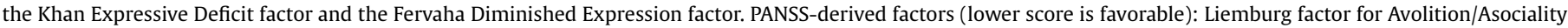

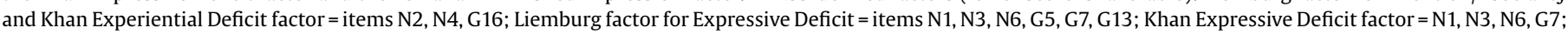

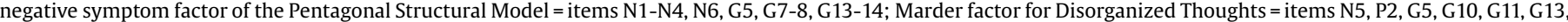

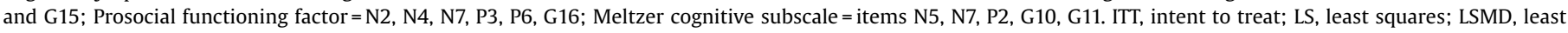
squares mean difference; MMRM; mixed-effects model for repeated measures; PANSS, Positive and Negative Syndrome Scale. 


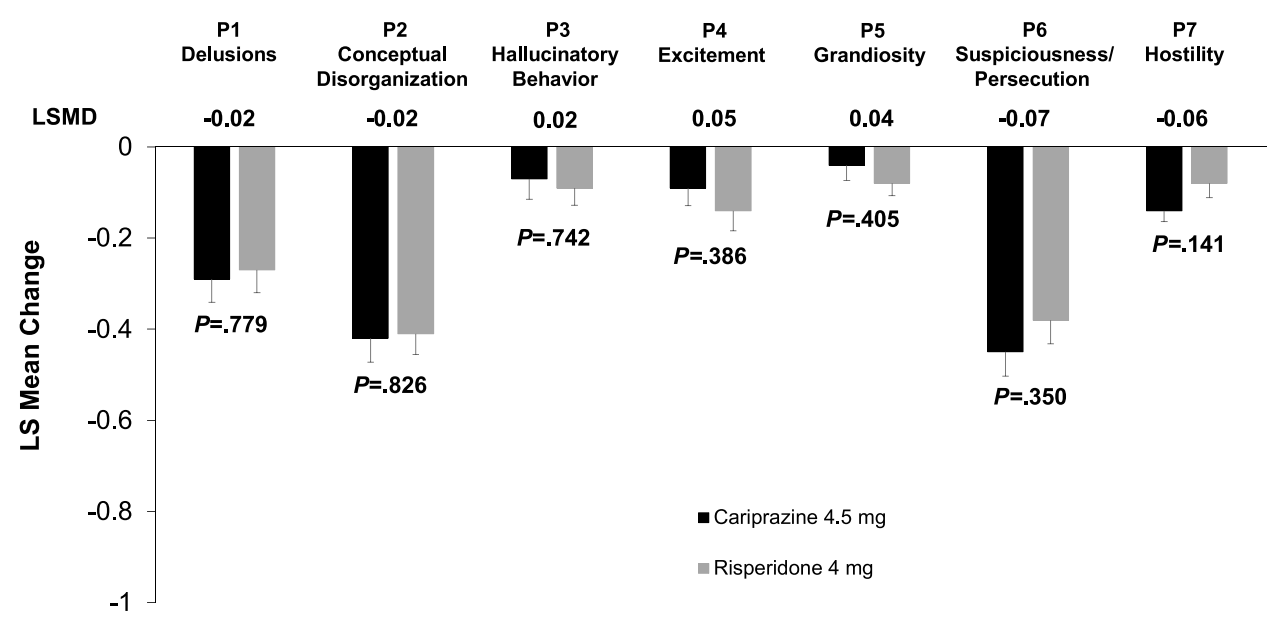

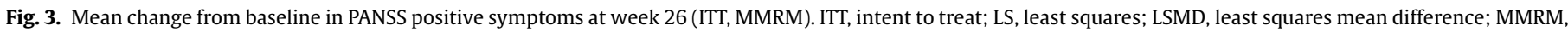
mixed-effects model for repeated measures; PANSS, Positive and Negative Syndrome Scale.

were statistically significant in favor of cariprazine versus risperidone on the Marder factor for Disorganized Thoughts $(-4.16$ vs $-3.53 ; P=.05)$, the Prosocial Functioning factor $(-4.94$ vs $-4.15 ; P=.014)$, and the Meltzer Cognitive subscale ( -3.13 vs -2.60 ; $P=.028$ ) (Fig. 2).

\subsubsection{Demonstrating that negative symptom change is genuine: pseudospecificity analyses}

In prospective analysis of the PANSS-FSPS, mean change from baseline at week 26 was the same for cariprazine and risperidone (-1.1; $P=.963)$, providing primary evidence for the lack of pseudospecific change in negative symptoms related to positive symptom improvement. In post hoc analyses, these results were supported by small and similar between-group mean changes on the individual positive items included in the PANSS-FSPS (P1, P3, P5, P6) (Fig. 3); mean change in unusual thought content, a general item included in the PANSS-FSPS (G9), was -0.24 for cariprazine and -0.26 for risperidone, with no significant between-group difference noted.

Post hoc analyses of additional factors related to pseudospecifity also supported primary evidence that changes in negative symptoms were not secondary to changes in symptoms from other domains. Namely, changes were small and similar for cariprazine and risperidone on the PANSS-derived Marder factors for Depression/Anxiety, Uncontrolled Excitement/Hostility, and Positive Symptoms (Fig. 4).
Additionally, small mean changes (range, -0.02 to 0.03 ) on each of the first 8 items of the SAS were not statistically different for cariprazine and risperidone, showing that improvement in negative symptoms was not an artifact of treatment-related differences in EPS liability. Of note, mean changes from baseline in CDSS total score were also small and not significantly different for cariprazine $(-0.28)$ and risperidone $(-0.22 ; P=.66)$, providing prospective evidence that improvement in negative symptoms was not pseudospecific to improvement in depressive symptoms [22].

\section{Discussion}

Heterogeneity in schizophrenia pathology contributes to the challenges associated with understanding and treating negative symptoms. To further explore the effectiveness of cariprazine versus risperidone in patients with schizophrenia and PPNS, we conducted post hoc analyses of PANSS individual items and PANSS-derived factors using data from the prospective negative symptom study. Differences on most individual items and all factors relevant to negative symptoms, cognitive symptoms, and social functioning were statistically significant in favor of cariprazine versus risperidone. Collectively, no significant differences were seen on pseudospecificity measures (ie, positive symptoms, depression, EPS) that would suggest that negative symptom improvement was due to changes in other symptom domains, supporting a genuine treatment effect for cariprazine in negative symptom improvement.

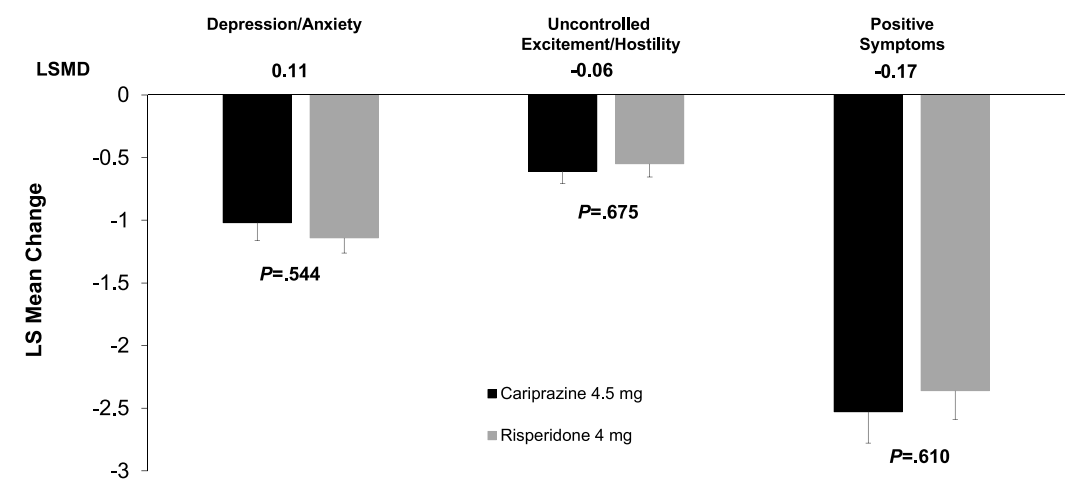

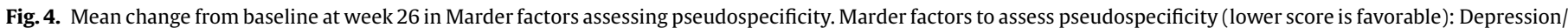

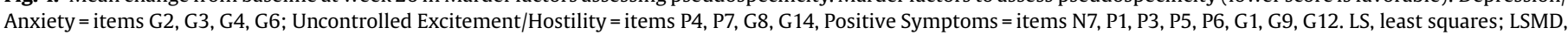
least squares mean difference. 
Despite some overlap among the 5 A's, affective flattening, alogia, anhedonia, asociality, and avolition have been identified as key constructs of negative symptoms, with evidence suggesting separate neurobiological underpinnings that may represent different therapeutic targets [8,12]. Hypotheses regarding the pathogenesis of blunted affect include abnormalities in identifying emotion, perception of nonverbal cues, and deficits in motor activity; interestingly, since decreased emotional expression is observed in medicated and nonmedicated patients alike, blunted affect cannot just be attributed to antipsychotic-related effect [37-40]. In our post hoc analysis, a significant between-group difference in change from baseline on PANSS item N1 (blunted affect) was noted, suggesting improvement in this fundamental construct for cariprazine- versus risperidone-treated patients.

Several mechanisms, including working memory deficit, general fluency disturbance, and word finding difficulties [41], have been proposed to explain alogia. On the PANSS, alogia is assessed by item N6 (lack of spontaneity/flow of conversation) through observed reduction in the normal flow of conversation associated with apathy, avolition, defensiveness, or cognitive deficit. In our analysis, although a greater than 1-point improvement from baseline was observed in both treatment groups, no significant between-group difference was seen on the alogia item, suggesting that risperidone may have also had some efficacy in this domain.

Anhedonia has traditionally been a key feature of both depression and schizophrenia [14]. Neurobehavioral models differentiate between consummatory and anticipatory pleasure [11], with research suggesting that schizophrenia may be characterized by intact consummatory pleasure, but impaired anticipatory pleasure [11]. This distinction may be important when evaluating functional outcomes in patients with schizophrenia since inability to anticipate a rewarding experience may underlie impaired initiative or incapacity to seek pleasant activities. Unlike some psychometric scales that directly measure anhedonia in schizophrenia $[13,16,42]$, no specific PANSS item evaluates anhedonia, which limits the ability of this scale to assess change in this key construct.

Asociality, which may predate the onset of schizophrenia [43], is generally regarded as social amotivation according to supportive evidence from factor analyses where it loads on the same factor as avolition $[10,44,45]$. Since people with schizophrenia compared with healthy individuals may have fewer opportunities to participate in social interaction because of external factors (eg, fewer intact relationships, stigma) [12,45], assessment of asociality should include both reduction in social activity and decreased interest in forming relationships [14]. In our analysis, changes from baseline were significantly different for cariprazine versus risperidone on PANSS items that measure asociality (poor rapport and passive/apathetic social withdrawal), with results contributing to significant improvement for cariprazine on the PANSS-FSNS and the PSM Negative Symptom factor.

Finally, studies suggest a key role for avolition in the relationship between negative symptoms and impaired functional outcomes $[7,46,47]$. The PANSS emotional withdrawal item (N2) assesses avolition through reports and observation of a patient's interest in their surroundings, which may make it challenging to assess reduced initiation and persistence of goal-directed activity that is not socially oriented. Change from baseline in emotional withdrawal was significantly different in favor of cariprazine versus risperidone, with results again contributing to improvement for cariprazine on several negative symptom factors.

Several studies support a stable 2-factor model [48-54], with key negative symptoms grouping into avolition/apathy and diminished expression domains that may be associated with different neurobiological abnormalities and psychosocial outcomes [8]. Namely, diminished expression may have a stronger association with nonsocial and neuropsychological function [30], while avolition/apathy is theorized to have a direct impact on functional outcomes in schizophrenia [46]. Of interest, our post hoc analyses found significant differences at week 26 in favor of cariprazine versus risperidone on PANSS-derived Expressive Deficits and Avolition/Asociality factors, which both supports prospective PANSS-FSNS and PSP results, and suggests that cariprazine has broad-spectrum pharmacological properties that improve symptomatic and functional aspects of negative symptoms. Given that functional impairment is an enormous burden for patients with negative symptoms [55], effective treatment can only be considered clinically relevant if symptom improvement translates into improved patient functioning.

In our analyses, significant differences in favor of cariprazine were also seen on factors assessing domains other than negative symptoms (disorganized thought, cognition, prosocial functioning), suggesting that improvements for cariprazine-treated patients were not limited to one domain. Small changes and no statistical differences between cariprazine and risperidone on factors for Depression/Anxiety, Uncontrolled Excitement/Hostility, and Positive Symptoms support a genuine treatment effect for cariprazine and the lack of pseudospecific change to explain negative symptom improvement.

Although post hoc analyses have inherent limitations, they allowed for single item and dimensional evaluation of PPNS in patients with stable schizophrenia who were treated with cariprazine or risperidone. Interpretation of our results are limited by the lack of placebo control. As is typical in post hoc evaluations, $P$ values were not adjusted for multiple comparisons, which could allow random chance to play a role in determining statistically significant differences. Since patients included in the prospective study had stable schizophrenia and PPNS, results may not be generalizable to other patient populations. Interpretation of factor analyses for negative symptoms may be limited by the inclusion of items that map inconsistently or may no longer be considered part of the negative symptom domain (ie, stereotyped thinking, difficulty in abstract thinking). This may help explain the lack of effect for cariprazine on item N7 (stereotyped thinking) in the individual item analysis. Additionally, item G5 (mannerisms and posturing) is included in the Liemburg Expressive Deficits factor and the PSM negative symptom factor although it is not generally regarded as a negative symptom. Although the PANSS is widely used in clinical trials, it is subject to psychometric limitations, including the lack of an anhedonia item. Further, since avolition is also poorly assessed by the PANSS, the differential effect of cariprazine and risperidone in this domain cannot be proven or excluded by our analysis. The PANSS-FSNS is a fully validated measure of negative symptom change [24], and although it was the only scale used to assess negative symptom improvement in the prospective trial, this study served regulatory purposes and use of a PANSS negative symptom outcome measure was specifically requested by authorities. Finally, although significant improvement was observed for cariprazine versus risperidone on most outcomes, this does not negate the possibility that risperidone also had some treatment effect.

The 5 A's provide an important framework for conceptualizing the multidimensional aspects of negative symptoms in schizophrenia. Post hoc analysis of data from patients with schizophrenia and PPNS demonstrated significant improvement for cariprazine over risperidone on PANSS negative symptom items and PANSSderived factors related to some of these key constructs. Research suggesting that clusters of individual items may represent different fundamental pathophysiological mechanisms of negative symptoms indicates that improvement across symptoms and 
factors may imply broad-spectrum efficacy for cariprazine. Small changes in positive symptoms, depressive symptoms, and EPS support our assertion that negative symptom improvement was a genuine cariprazine treatment effect that did not occur secondary to improvement in other symptom domains. Given the lack of negative symptom treatment options, these results are clinically interesting and may be another step toward addressing a considerable unmet need in schizophrenia.

\section{Contributors}

I. Laszlovszky, B. Szatmári, Á. Barabássy, K. Acsai, E. Szalai, J. Harsányi, and G. Németh contributed to the study design, analysis, and interpretation of data. W. Fleischhacker, S. Galderisi, W. Earley, and M. Patel contributed to the analysis and interpretation of the data. All authors revised and approved the final version of the manuscript.

\section{Declaration of interest}

W. Wolfgang Fleischhacker received grants and personal fees from Janssen-Cilag, grants and personal fees from Otsuka, grants and personal fees from Lundbeck, personal fees from Roche, personal fees from Takeda, personal fees from Amgen, personal fees from Teva, personal fees from Targacept, personal fees from Richter, grants and personal fees from Boehringer Ingelheim, outside the submitted work.

Silvana Galderisi received honoraria and advisory board or consulting fees from Angelini Acraf, Gedeon Richter, F Hoffman-La Roche, Janssen Pharmaceuticals, Lundbeck, Otsuka, and Pierre Fabre.

István Laszlovszky, Ágota Barabássy, Balázs Szatmári, Judit Harsányi, Erzsébet Szalai, and György Németh report personal fees from Gedeon Richter Plc., outside the submitted work. Dr. Németh and Dr. Laszlovszky have issued patents for cariprazine; Dr. Szatmári has a patent pending for cariprazine.

Mehul Patel and Willie Earley are employees of Allergan.

\section{Funding}

This study was funded by Gedeon Richter Plc..

\section{Acknowledgements}

The authors would like to thank Carol Brown, MS, of Prescott Medical Communications Group, a contractor of Gedeon Richter Plc, for providing writing and editorial assistance.

\section{References}

[1] Millan MJ, Fone K, Steckler T, Horan WP. Negative symptoms of schizophrenia clinical characteristics, pathophysiological substrates, experimental models and prospects for improved treatment. Eur Neuropsychopharmacol 2014;24:645-92.

[2] APA. Diagnostic and Statistical Manual of Mental Disorders. fifth edition Arlington, VA: American Psychiatric Association; 2013.

[3] Fervaha G, Foussias G, Agid O, Remington G. Impact of primary negative symptoms on functional outcomes in schizophrenia. Eur Psychiatry 2014;29:449-55.

[4] Fervaha G, Foussias G, Agid O, Remington G. Motivational deficits in early schizophrenia: prevalent, persistent, and key determinants of functional outcome. Schizophr Res 2015;166:9-16.

[5] Foussias G, Agid O, Fervaha G, Remington G. Negative symptoms of schizophrenia: clinical features, relevance to real world functioning and specificity versus other CNS disorders. Eur Neuropsychopharmacol 2014;24:693-709.

[6] Galderisi S, Bucci P, Mucci A, Kirkpatrick B, Pini S, Rossi A, et al. Categorical and dimensional approaches to negative symptoms of schizophrenia: focus on long-term stability and functional outcome. Schizophr Res 2013;147:157-62.

[7] Galderisi S, Rossi A, Rocca P, Bertolino A, Mucci A, Bucci P, et al. Italian Network for Research on Psychoses. The influence of illness-related variables, personal resources and context-related factors on real-life functioning of people with schizophrenia. World Psychiatry 2014;13:275-87.
[8] Bucci P, Galderisi S. Categorizing and assessing negative symptoms. Curr Opin Psychiatry 2017;30:201-8.

[9] Galderisi S, Mucci A, Buchanan RW, Arango C. Negative symptoms of schizophrenia: new developments and unanswered research questions. Lancet Psychiatry 2018;5:664-77.

[10] Blanchard JJ, Cohen AS. The structure of negative symptoms within schizophrenia: implications for assessment. Schizophr Bull 2006;32:238-45.

[11] Horan WP, Kring AM, Gur RE, Reise SP, Blanchard JJ. Development and psychometric validation of the Clinical Assessment Interview for Negative Symptoms (CAINS). Schizophr Res 2011;132:140-5.

[12] Kirkpatrick B, Fenton WS, Carpenter Jr WT, Marder SR. The NIMH-MATRICS consensus statement on negative symptoms. Schizophr Bull 2006;32:214-9.

[13] Kring AM, Gur RE, Blanchard JJ, Horan WP, Reise SP. The Clinical Assessment Interview for Negative Symptoms (CAINS): final development and validation. Am J Psychiatry 2013;170:165-72.

[14] Marder SR, Galderisi S. The current conceptualization of negative symptoms in schizophrenia. World Psychiatry 2017;16:14-24.

[15] Kay SR, Fiszbein A, Opler LA. The Positive and Negative Syndrome Scale (PANSS) for schizophrenia. Schizophr Bull 1987;13:261-76.

[16] Kirkpatrick B, Strauss GP, Nguyen L, Fischer BA, Daniel DG, Cienfuegos A, et al. The Brief Negative Symptom Scale: psychometric properties. Schizophr Bull 2011;37:300-5.

[17] Gyertyán I, Kiss B, Sághy K, Laszy J, Szabó G, Szabados T, et al. Cariprazine (RGH-188), a potent D3/D2 dopamine receptor partial agonist, binds to dopamine D3 receptors in vivo and shows antipsychotic-like and procognitive effects in rodents. Neurochem Int 2011;59:925-35.

[18] Kiss B, Horváth A, Némethy Z, Schmidt E, Laszlovszky I, Bugovics G, et al. Cariprazine (RGH-188), a dopamine $\mathrm{D}(3)$ receptor-preferring, $\mathrm{D}(3) / \mathrm{D}(2)$ dopamine receptor antagonist-partial agonist antipsychotic candidate: in vitro and neurochemical profile. J Pharmacol Exp Ther 2010;333:328-40.

[19] Girgis RR, Slifstein M, D'Souza D, Lee Y, Periclou A, Ghahramani P, et al Preferential binding to dopamine D3 over D2 receptors by cariprazine in patients with schizophrenia using PET with the D3/D2 receptor ligand [(11)C](+)-PHNO. Psychopharmacology (Berl) 2016;233:3503-12.

[20] Duric V, Banasr M, Franklin T, Lepack A, Adham N, Kiss B, et al. Cariprazine exhibits anxiolytic and dopamine D3 receptor-dependent antidepressant effects in the chronic stress model. Int J Neuropsychopharmacol 2017;20:788-96.

[21] Zimnisky R, Chang G, Gyertyán I, Kiss B, Adham N, Schmauss C. Cariprazine, a dopamine $\mathrm{D}(3)$-receptor-preferring partial agonist, blocks phencyclidineinduced impairments of working memory, attention set-shifting, and recognition memory in the mouse. Psychopharmacology (Berl) 2013;226: 91-100.

[22] Németh G, Laszlovszky I, Czobor P, Szalai E, Szatmari B, Harsanyi J, et al. Cariprazine versus risperidone monotherapy for treatment of predominant negative symptoms in patients with schizophrenia: a randomised, doubleblind, controlled trial. Lancet 2017;389:1103-13.

[23] Marder SR, Daniel DG, Alphs L, Awad AG, Keefe RS. Methodological issues in negative symptom trials. Schizophr Bull 2011;37:250-4.

[24] Marder SR, Davis JM, Chouinard G. The effects of risperidone on the five dimensions of schizophrenia derived by factor analysis: combined results of the North American trials. J Clin Psychiatry 1997;58:538-46.

[25] Nasrallah H, Morosini P, Gagnon DD. Reliability, validity and ability to detect change of the Personal and Social Performance Scale in patients with stable schizophrenia. Psychiatry Res 2008;161:213-24.

[26] APA. Diagnostic and Statistical Manual of Mental Disorders. fourth edition Washington, DC: American Psychiatric Association; 2000 Text Revision.

[27] Mohr PE, Cheng CM, Claxton K, Conley RR, Feldman JJ, Hargreaves WA, et al. The heterogeneity of schizophrenia in disease states. Schizophr Res 2004:71:83-95.

[28] Addington D, Addington J, Maticka-Tyndale E. Assessing depression in schizophrenia: the Calgary Depression Scale. Br J Psychiatry Suppl 1993;39-44.

[29] Simpson GM, Angus JW. A rating scale for extrapyramidal side effects. Acta Psychiatr Scand 1970;212(Suppl):11-9.

[30] Liemburg E, Castelein S, Stewart R, van der Gaag M, Aleman A, Knegtering H, et al. Outcome of Psychosis I. Two subdomains of negative symptoms in psychotic disorders: established and confirmed in two large cohorts. J Psychiatr Res 2013;47:718-25.

[31] Khan A, Liharska L, Harvey PD, Atkins A, Ulshen D, Keefe RSE. Negative symptom dimensions of the positive and negative syndrome scale across geographical regions: implications for social, linguistic, and cultural consistency. Innov Clin Neurosci 2017;14:30-40.

[32] White L, Harvey PD, Opler L, Lindenmayer JP. Empirical assessment of the factorial structure of clinical symptoms in schizophrenia. A multisite, multimodel evaluation of the factorial structure of the Positive and Negative Syndrome Scale. The PANSS Study Group. Psychopathology 1997;30:263-74.

[33] Fervaha G, Foussias G, Agid O, Remington G. Motivational and neurocognitive deficits are central to the prediction of longitudinal functional outcome in schizophrenia. Acta Psychiatr Scand 2014;130:290-9.

[34] Purnine DM, Carey KB, Maisto SA, Carey MP. Assessing positive and negative symptoms in outpatients with schizophrenia and mood disorders. J Nerv Ment Dis 2000;188:653-61.

[35] Meltzer HY, Cucchiaro J, Silva R, Ogasa M, Phillips D, Xu J, et al. Lurasidone in the treatment of schizophrenia: a randomized, double-blind, placebo- and olanzapine-controlled study. Am J Psychiatry 2011;168:957-67. 
[36] Kenward MG, Roger JH. Small sample inference for fixed effects from restricted maximum likelihood. Biometrics 1997;53:983-97.

[37] Gur RE, Kohler CG, Ragland JD, Siegel SJ, Lesko K, Bilker WB, et al. Flat affect in schizophrenia: relation to emotion processing and neurocognitive measures. Schizophr Bull 2006;32:279-87.

[38] Kring AM, Moran EK. Emotional response deficits in schizophrenia: insights from affective science. Schizophr Bull 2008;34:819-34.

[39] Lepage M, Sergerie K, Benoit A, Czechowska Y, Dickie E, Armony JL. Emotional face processing and flat affect in schizophrenia: functional and structural neural correlates. Psychol Med (Paris) 2011;41:1833-44.

[40] Aghevli MA, Blanchard JJ, Horan WP. The expression and experience of emotion in schizophrenia: a study of social interactions. Psychiatry Res 2003;119:261-70.

[41] Berenbaum H, Kerns JG, Vernon LL, Gomez JJ. Cognitive correlates of schizophrenia signs and symptoms: III. Hallucinations and delusions. Psychiatry Res 2008;159:163-6.

[42] Andreasen NC. The Scale for the Assessment of Negative Symptoms (SANS) conceptual and theoretical foundations. Br I Psychiatry Suppl 1989;49-58.

[43] Cannon M, Jones P, Gilvarry C, Rifkin L, McKenzie K, Foerster A, et al. Premorbid social functioning in schizophrenia and bipolar disorder: similarities and differences. Am J Psychiatry 1997;154:1544-50.

[44] Kirkpatrick B. Progress in the study of negative symptoms. Schizophr Bull 2014;40(Suppl 2):S101-6.

[45] Messinger JW, Tremeau F, Antonius D, Mendelsohn E, Prudent V, Stanford AD, et al. Avolition and expressive deficits capture negative symptom phenomenology: implications for DSM-5 and schizophrenia research. Clin Psychol Rev 2011;31:161-8.

[46] Foussias G, Remington G. Negative symptoms in schizophrenia: avolition and Occam's razor. Schizophr Bull 2010;36:359-69.
[47] Galderisi S, Rucci P, Kirkpatrick B, Mucci A, Gibertoni D, Rocca P, et al. Italian network for research on psychoses. Interplay among psychopathologic variables, personal resources, context-related factors, and real-life functioning in individuals with schizophrenia: a network analysis. JAMA Psychiatry 2018;75:396-404.

[48] Keefe RS, Harvey PD, Lenzenweger MF, Davidson M, Apter SH, Schmeidler J, et al. Empirical assessment of the factorial structure of clinical symptoms in schizophrenia: negative symptoms. Psychiatry Res 1992;44:153-65.

[49] Kelley ME, van Kammen DP, Allen DN. Empirical validation of primary negative symptoms: independence from effects of medication and psychosis. Am J Psychiatry 1999;156:406-11.

[50] Malla AK, Takhar JJ, Norman RM, Manchanda R, Cortese L, Haricharan R, et al. Negative symptoms in first episode non-affective psychosis. Acta Psychiatr Scand 2002;105:431-9.

[51] Minas IH, Klimidis S, Stuart GW, Copolov DL, Singh BS. Positive and negative symptoms in the psychoses: principal components analysis of items from the Scale for the Assessment of Positive Symptoms and the Scale for the Assessment of Negative Symptoms. Compr Psychiatry 1994;35:135-44.

[52] Mueser KT, Sayers SL, Schooler NR, Mance RM, Haas GL. A multisite investigation of the reliability of the Scale for the Assessment of Negative Symptoms. Am J Psychiatry 1994;151:1453-62.

[53] Peralta V, Cuesta MJ. Negative symptoms in schizophrenia: a confirmatory factor analysis of competing models. Am J Psychiatry 1995;152:1450-7.

[54] Toomey R, Kremen WS, Simpson JC, Samson JA, Seidman LJ, Lyons MJ, et al. Revisiting the factor structure for positive and negative symptoms: evidence from a large heterogeneous group of psychiatric patients. Am J Psychiatry 1997; $154: 371-7$.

[55] Buchanan RW. Persistent negative symptoms in schizophrenia: an overview. Schizophr Bull 2007;33:1013-22. 